\title{
Analysis on the Impact of Innovation and Entrepreneurship Education on the Employment Ability of Fashion Design Professionals
}

\author{
Tian Lan ${ }^{1, a}$ and Xiufang Zhang ${ }^{2, b}$ \\ ${ }^{1}$ Changchun University of Technology Changchun, Jilin, China 130000 \\ ${ }^{2}$ Fine Arts Academy of Northeast Normal University Changchun, Jilin, China 130000 \\ a 16617636@qq.com, b547675374@qq.com
}

Keywords: Innovation and Entrepreneurship; Costume design; Employment; Integration approach; Education quality

\begin{abstract}
Our country has begun to vigorously develop the creative industry since the GDP leaped to the second in the world in 2010. The clothing industry is important in the creative industry. We shoulder heavy responsibilities in the development of clothing specialty. Under this background, it is necessary to find new ways and methods for the clothing specialty to strengthen the cooperation between school and enterprise and improve the quality of applied talents. With the rapid development of economy, the pace of people's life has become faster, social competition has become more intense, and the talents truly meeting the social development with high-quality are that the community needs. In terms of talent cultivation, the idea of innovation and entrepreneurship already has been the key concept of the education of colleges and universities in the new period. Especially under the influence of "double creation", we need to pay more attention to the cultivation of students' innovation and entrepreneurship. The development of the new times can not be separated from innovation, students only to enhance their ability of innovation can be better adapt to social development and competition. This paper made a brief exposition on the innovation and entrepreneurship education, and put forward the impact of the innovation and entrepreneurship education on the employment rate of colleges, hoping to provide inspiration and reference for the relevant persons.
\end{abstract}

\section{Introduction}

In recent decades, the rapid economic development in China is obvious to all, people's living standards have indeed been greatly improved, material requirements are also continually increasing, the garment industry is one of the typical industry emerged. To this end, China has also formed an increasingly mature clothing education system in recent decades, providing a large number of relevant personnel for the development of China's garment industry and playing a huge role in promoting this industry. The clothing in new era is not only the demand for warm features, more for requirements in the aspect of the design innovation, which requires the fashion design to continuously innovate and reform in the style, only do like that, it could adapt to social development and people continually raising demand. Therefore, we must start from the source of talent education, reform and innovating traditional education model, give full play to the guiding role of innovation and entrepreneurship education, to enhance students' awareness of innovation and entrepreneurship, so as to better adapt to the development of the times.

\section{The Related Introduction on Innovation and Entrepreneurship Education}

Concept. Innovative education is a kind of education to cultivate students to give full play to their initiative and creativity. Entrepreneurship education is a kind of education to cultivate talents to obtain entrepreneurial ability. Innovation and entrepreneurship education is the quality education to treat fully developing and cultivating innovative thinking and entrepreneurial ability of high-quality talent as the goal. 


\section{The Value and Significance of Innovating Entrepreneurship Education}

To Adapt to the Development Trend of Market Economy. With the deepening of economic reform, international competition has become increasingly fierce, the country who wants to be invincible in the competition must improve the core competitiveness, therefore, it should vigorously cultivate high-quality talent. The major colleges and universities should treat vigorously cultivating high-quality talent as the primary task of education, university personnel, on the one hand, should have excellent professional knowledge and skills, on the other hand, they should also have ability of appropriate innovation and entrepreneurship, so as to be able to actual development of social competition demand. According to the relevant survey, China's garment design industry have a large demand gap in the innovative talents, therefore, colleges should strengthen the innovation and entrepreneurship education of fashion design students, when promoting their own education development, can also meet the current economic development needs.

To Achieve the Self-worth of College Students. The times is in the continuous development, people also have a huge change in following, the desire of today's college students to achieve selfvalue is increasingly strong. In order to meet this kind of the needs, it should be to implement innovation and entrepreneurship education, through innovation and entrepreneurship, students could choose their own advantageous areas, give full play to innovative thinking, so that their own level get an effective promotion. In this education, the comprehensive quality of college students are treated as the focus of training, which provide a stage for the development of individual students, the potential has also been fully stimulated to obtain the ability to adapt to the times and development and better promote our country's modernization construction.

To Ease Social Employment Pressure. With the continuous development of social economy, economic and industrial structure get continuous transformation and upgrading in the development process, so the requirements of talent is constantly changing, leading to more uncertain factors affecting the current employment of college students. In order to cope with such a situation, we need to carry out active development of independent entrepreneurship. Colleges lay the foundation for independent entrepreneurship through innovation and entrepreneurship education, and fully tap and cultivate students' innovative ability. Through carrying out a number of entrepreneurial activities, we can save jobs, at the same time, can also create more new jobs, thus driving employment.

\section{The Current Situation of Innovation and Entrepreneurship Education}

Policy out of College Strategy. With the vigorous development of educational reform, China's major colleges and universities are also in full swing carrying out education and teaching reform, and constantly strengthen the efforts of innovation and entrepreneurship education, although there is a certain degree of harvest and progress, but there are still some places and colleges lack of the attention to innovation and entrepreneurship education, the concept of innovation and entrepreneurship education is relatively backward, but not integrate the innovation and entrepreneurship education into professional education, leading to serious disruption of the practice. In addition, the relevant teachers seriously lack corresponding awareness and ability of innovation and entrepreneurship education, and therefore the education method is still no innovation, there is no corresponding business platform, the guidance of entrepreneurship education is not perfect. In view of the above serious situation, the important problem to be solved at this stage of the innovation and entrepreneurship education is the establishment and perfection of innovation and entrepreneurship education system.

Change the Concept of Entrepreneurship Education, to Build a Vocational Entrepreneurship Education Platform. In terms of the actual situation of current education, innovation is only an adjunct to the main teaching content of many colleges. There is no real inclusion of entrepreneurship education into the personnel training system and normative education, even if there are already some the pilot institutions, most of them did not achieve the teaching model of innovation, the education still remain in the scope of elective courses, only the theoretical level of education, the lack of appropriate business practice platform and space, did not achieve the 
combination of vocational education and entrepreneurship education. Therefore, in order to achieve the combination of professional education and entrepreneurship education, the relevant pilot schools should have the corresponding provisions, requiring students to complete the business must complete the class learning and business practice certification, access to the corresponding provisions of the credits. In the corresponding vocational teaching system, we must put vocational entrepreneurship, entrepreneurial practice and SME entrepreneurship management courses into the required courses, through these courses to teach students entrepreneurial knowledge, and through practice to enhance students' practical ability. At the same time, the major institutions should pay attention to the construction of students' entrepreneurship platform, so as to better promote students to apply their knowledge, to test the authenticity of textbook knowledge with practice, to strengthen the practical ability of exercise and promotion, and thus better promote students to start their own business. In this regard, many colleges have made a demonstration and set an example, increasing the intensity of entrepreneurship education, attaching attention to the importance of entrepreneurship education in the new situation from the fundamental, through the implementation of relevant measures, they are access to gratifying results.

Expedition Class to Achieve Innovation and Entrepreneurship Education. In recent years, social development is rapid, at the time of promoting of people's living standards, enhancing the competitive pressure has become extremely fierce, college students are currently facing enormous employment pressure, a series of problems have emerged. In the face of these problems, the country will treat solving the problem of young people's employment as the main body of the people's livelihood work, colleges should also conscientiously implement the relevant national policy, to promote employment through the policy, when broadening the employment channel, it should be to achieve the fairness of employment, to encourage students to start their own business

\section{The Integration Approach of Colleges Innovation and Entrepreneurship Education with Clothing Design Vocational Education}

Pay Attention to the Implementation of Entrepreneurship Education, Innovate Personnel Training Program. It is a long-term and complicated system engineering in terms of entrepreneurial education itself. To improve the quality of entrepreneurship education, we must establish a scientific concept of entrepreneurial education, innovate the personnel training program and attach importance to the cultivation of professional talents, at the same time, we should put innovative personnel training on the same important position. Bringing the school's training system into the entrepreneurial high-quality personnel training, improve the corresponding training programs, develop training programs, innovate entrepreneurship education into all aspects of teaching, so that it truly become a key link in the training of personnel, only do like that, can we really achieve efficient training of entrepreneurial talent.

Deepen the Reform of Teaching Content, Construct Perfect Curriculum System. In order to further enhance the effectiveness and quality of innovation and entrepreneurship education, the teaching content reform should be further deepened, and the combination of professional education and entrepreneurship education should be achieved. In the teaching of professional courses, consciously introduce the education of entrepreneurial awareness and psychological entrepreneurship and other aspects, highlights of education should be the cultivation the entrepreneurial quality and entrepreneurial knowledge. We should not make innovative entrepreneurship education and professional education independent, but should integrate them into the professional teaching system, and actively cooperate with the relevant enterprises, build a suitable platform for the innovative curriculum, at the time of protecting the teaching, we also make entrepreneurial quality and skills of students be further improved. In the learning system, we can give the appropriate flexibility for entrepreneurship education, to lay the basis for the combination of innovation and entrepreneurship education, in addition to learning knowledge, students can also use other time for extracurricular practice activities, greatly stimulating the enthusiasm of entrepreneurship. 
Increase the Construction of Teachers, Fit the needs of Entrepreneurship Education. In the teaching of colleges, the important position of teachers can not be ignored, and they play an important role in the education of the organizers and guiders. Therefore, it is necessary to start from the teachers' team if we want to strengthen the innovation and entrepreneurship education, the specific points as follows: First, a large number of excellent teachers should be select, to strengthen the teacher's entrepreneurial awareness, knowledge and skills training, teachers will be sent to innovative enterprises to carry out the corresponding innovation and entrepreneurship practice, advocating teachers to participate in innovation and entrepreneurship education academic exchanges and other activities. Second, improve the relevant incentive system to provide more entrepreneurial practice platform for the majority of teachers, they can practice, learn and upgrade in the actual market, to better guide students to lay the foundation for practice and entrepreneurship. Third, inviting excellent entrepreneurs to the school to serve, teach, etc., providing more direct contact for students with them and learning opportunities, and enhance the level of entrepreneurship teachers.

Carry out Entrepreneurial Practice Activities, Enhance Quality of Entrepreneurship Education. First, in the establishment of the campus culture system, entrepreneurial culture will be incorporated into the system, making the combination of entrepreneurship education and professional education through the entrepreneurial competition activities and organizations such as the organization and other forms of activities to enrich the students' entrepreneurial cultural activities, strengthen communication and learning among students through the relevant development of activities. Second, we can increase the construction of domestic and foreign entrepreneurship base to enhance the business platform and achieve the corresponding establishment and implementation of the park in campus, and achieve the construction of entrepreneurial market platform. Third, based on entrepreneurial project-oriented, to encourage students to go to the process of entrepreneurial practice, make them feel the whole business process with heart, summing up their own entrepreneurial experience to further enhance their entrepreneurial ability. At the same time, vocational colleges themselves should make full use of their existing resources, and they pay attention to the scientific nature and feasibility in the venture projects, and provide the corresponding business planning plan, to better guide the students' entrepreneurial practice. In addition to that. It also be open to the internal and external enterprises and the community, to develop and find suitable business practice projects for students.

\section{Conclusion}

In short, with the influx of a large number of university graduates and the current actual market situation, we can see that the current employment situation of college students is very grim. The major colleges and universities should start from the education to alleviate this situation, which requires the active development of innovation and entrepreneurship education. Fashion design profession is a major closely following the development of the times, must be through the integration of innovation and entrepreneurship education to improve the quality of talents, so as to enable students to achieve self-worth while also raising the employment rate, which is of great significance. However, in terms of the actual situation, college students innovation and entrepreneurship education is very complex, if want to carry out this education, we must combine with the actual situation of colleges to carry out continuous development, to explore a set of education model suitable for the situation of innovation and entrepreneurship, thus more efficient to delivery more excellent clothing design talent for the country .

\section{References}

[1] Li Yafeng, Chu Mingchang, Dou Wen-shu. Study on Innovation and entrepreneurship education of college students [J]. College, 2014 (12).

[2] Guo Wenjun. Study on innovation and entrepreneurship education integrated into vocational education of the clothing and apparel design [J]. Art Education, 2015.7 (18): 66-68. 
[3] Li Lixin. Research on innovation and entrepreneurship education of clothing and apparel design college students [J]. Liaoning Silk, 2015.6 (10): 123-125.

[4] Li Zekai. Thinking on the development of higher nursing education After China's accession to WTO [J]. Chinese Nursing, 2002 (37).

[5] Shen Xiaojun. Thinking on innovative entrepreneurship education integrated into the vocational education [J]. Small and Medium-sized Enterprise Management and Technology, 2015.7 (11): 55-57.

[6] Yang Lin. Thinking on vocational innovation education reform based on the development of garment industry and garment design[J]. Popular Literature (Academic Edition), 2015.8 (16): 144-145.

[7] Zheng Meihui. Research on marketization of college fashion design vocational education [J]. Popular Literature. 2015 (04).

[8] Chen Yugang. Thinking on implementation of entrepreneurship education of clothing design specialty in private colleges [J]. Textile Industry and Technology, 2014, 7 (11): 44-46.

[9] $\mathrm{Wu}$ Liangyong. Thinking on innovation and entrepreneurship education of art design professional in new era [J]. Modern Decoration, 2014, 7 (13): 133-134.

[10] Li Jiping, Liu Suzhen, Li Huiqing. Thinking on the training of 21 st century nursing undergraduate [J]. Modern Care, 2004 (1).

[11] Lu Yuzhi. Exploration of teaching design of costume design under the background of schoolenterprise cooperation-Taking Peina class of Hezhou college as an example [J]. Journal of Fine Arts Education. 2017 (01).

[12] Tang Genli, Wang Yanbo. Study on the path to cultivate innovation and entrepreneurship ability for college students [J]. Journal of Sichuan University of Technology, 2011 (6).

[13] Meng Hewei, Li Hui, Guqin. Analysis on college students innovation and entrepreneurship education [J]. Agricultural Network Information, 2011 (1).

[14] Liu Qiong. Thinking on clothing and costume design specialty integration into innovation and entrepreneurship education [J]. Science and Technology Guide (mid-term), 2016 (07): 23-24 +26 .

[15]Zhu Jinzhu. Study on the teaching reform of fashion design specialty in Colleges based on market demand[J]. Journal of Lanzhou College of Education, 2013(03) 